\title{
Fetal Plasma Leptin Concentrations: Relationship with Different Intrauterine Growth Patterns from 19 Weeks to Term
}

\author{
IRENE CETIN, PAOLA S. MORPURGO, TATJANA RADAELLI, EMANUELA TARICCO, \\ DONATELLA CORTELAZZI, MARIA BELLOTTI, GIORGIO PARDI, AND PAOLO BECK-PECCOZ \\ Department of Obstetrics and Gynecology, Ospedale San Paolo, Milan, Italy [I.C., T.R., E.T., M.B., G.P.]; \\ and Institute of Endocrine Sciences, Ospedale Maggiore IRCCS, University of Milano, \\ Milan, Italy [P.S.M., D.C., P.B.-P.]
}

\section{ABSTRACT}

\begin{abstract}
The relationship between in utero fetal growth and fetal leptin concentrations was investigated between 19 and $41 \mathrm{wk}$ in 40 normal (appropriate for gestational age, AGA) fetuses, in 25 intrauterine growth-restricted (IUGR) fetuses, and in 18 fetuses from gestational diabetic mothers (GDM), representing different intrauterine growth patterns. Umbilical venous plasma leptin concentrations were determined at the time of either in utero fetal blood sampling or delivery. Plasma leptin was measurable as early as 19 wk of gestation. A significant difference was observed between umbilical venous and arterial plasma leptin concentrations $(0.6 \pm 0.6 \mathrm{ng} / \mathrm{mL} ; p<0.01)$. In AGA and in IUGR fetuses, significant positive relationships were found between fetal leptin concentrations and both gestational age $(p<0.001)$ and fetal weight $(p<0.001)$. Leptin concentrations were significantly higher in AGA than IUGR only after $34 \mathrm{wk}(p<0.05)$, but leptin per kilogram fetal weight (leptin/kg) was not significantly different. In IUGR with abnormal umbilical arterial Doppler velocimetry and fetal heart rate, leptin/kg significantly higher than in IUGR with normal biophysical and biochemical parameters was
\end{abstract}

found ( $p<0.05$ ). Both circulating plasma leptin and leptin $/ \mathrm{kg}$ were significantly higher in GDM than in normal fetuses $(p<$ 0.001 ) and correlated with abdominal fat mass measured by ultrasound. No gender differences were observed in any group of fetuses. These findings indicate a clear relationship between fetal leptin concentrations and fetal fat mass. Data in severe IUGR suggest the presence of increased leptin concentrations associated with in utero signs of fetal distress. (Pediatr Res 48: 646-651, 2000)
Abbreviations
AGA, appropriate for gestational age
IUGR, intrauterine growth restricted
LGA, large for gestational age
GDM, gestational diabetes mellitus
PI, pulsatility index
FHR, fetal heart rate
FBS, fetal blood sampling

Leptin is a circulating polypeptide hormone expressed abundantly in the adipose tissue (1) that regulates body weight and energy expenditure through a negative feedback signal between the adipose tissue and the hypothalamic centers of satiety (2). In humans, there is a positive correlation between leptin and body fat content or body mass index (BMI), with a sexual dimorphism in its regulation at the same level of fatness or BMI, and significantly higher concentrations in females than in males $(3,4)$. Moreover, leptin deficiency is accompanied by reduced fertility in $o b / o b$ female mice and leptin treatment

Received December 29, 1999; accepted July 3, 2000

Correspondence and reprint requests: Irene Cetin, M.D., Obstetrics and Gynecology, San Paolo Department of Medicine, Surgery and Odontoiatry, University of Milano School of Medicine, via A. di Rudini' 8, 20142 Milano, Italy.

This work was partially supported by a European Economic Community grant (BMH498-3621) and a grant from the Italian Ministry of University and Scientific and Technologic Research (Ministero Università e Ricerca Scientifica e Tecnologica: MURST) and CNR (Consiglio Nazionale delle Ricerche). restored fertility along with decreased dietary intake, body weight, and fat mass (5). Recently, these data have been confirmed in a 9-y-old girl with congenital leptin deficiency treated with recombinant leptin that lead to a sustained reduction in body weight and percent body fat, which was associated with an increase in gonadotropin concentrations and pulsatility (6).

Leptin concentrations have been measured in cord blood of newborn infants and a significant relationship has been reported with fetal weight (7-11). Both fetal and placental production of leptin has been demonstrated, but the different contribution of these two compartments to umbilical leptin circulating levels is difficult to evaluate. Clapp and Kiess (12) have shown a more significant relationship between leptin in cord blood and neonatal fat mass than with birth weight, although they did not find a significant relationship with placental weight. On the other hand, Yura et al. (13) demonstrated 
a significantly positive leptin umbilical venous-arterial concentration difference and its rapid decline after birth, giving support to the hypothesis that the placenta is one of the major sources of leptin in the fetal circulation. A possible role of leptin as a regulator of fetal growth has been recently suggested as IUGR and large for gestational age fetuses presented respectively lower and higher leptin concentrations than normal fetuses $(10,11)$. However, in another study, leptin concentrations were higher in IUGR fetuses (9).

The purposes of this study were (1) to evaluate leptin concentrations in fetal blood of normal pregnancies from mid to late gestation and (2) to measure leptin concentrations in fetuses with different in utero growth patterns from IUGR to gestational diabetic pregnancies, reflecting a wide range of fetal fat mass.

\section{MATERIALS AND METHODS}

The studies were performed in the Department of Obstetrics and Gynecology of the San Paolo Hospital. The protocol was approved by the San Paolo Institute Board. Informed consent was obtained from all pregnant women.

\section{Clinical Studies}

Eighty-three pregnancies were studied between 19 and 41 wk of gestation. The characteristics of the population are presented in Table 1. Gestational age was calculated from the last menstrual period and confirmed by an ultrasonographic examination performed before $20 \mathrm{wk}$ of gestation. Patterns of intrauterine fetal growth were defined by ultrasound performed during pregnancy and confirmed at birth. In 40 normal pregnancies, fetuses were AGA at birth according to Italian standards for birth weight and gestational age (14).

Twenty-five pregnancies carrying IUGR fetuses were identified by serial ultrasound examination. Measurements of abdominal circumferences of IUGR fetuses were below the 10th percentile of reference values for fetuses of similar ages (15). Growth restriction was confirmed at birth if the neonatal weight was below the 10th percentile according to Italian standards for birth weight and gestational age (14). In AGA and IUGR pregnancies, a $50 \mathrm{~g}$ oral glucose challenge test was performed between 24 and 28 wk of gestation to exclude gestational diabetes. Eighteen pregnancies with GDM were diagnosed in the presence of a $100 \mathrm{~g}$ oral glucose tolerance test with two or more values outside the normal ranges (16). Serial ultrasound examinations were performed in GDM, and a measurement of in utero fetal fat mass was taken by measuring the thickness of abdominal wall at the level of the abdominal circumference.

Fetal blood sampling. In forty-eight pregnancies an umbilical venous sample was obtained at the time of FBS, performed between 19 and 38 wk of gestation, after an overnight fast. Two groups were studied: (1) 28 pregnancies carried AGA fetuses that underwent FBS for prenatal diagnosis (rapid karyotyping, maternal infections, maternal thrombocytopenia) and demonstrated absence of the pathology;(2) 20 pregnancies were complicated by IUGR, and FBS was performed for rapid karyotyping and biochemical assessment as part of our routine clinical protocol $(17,18)$. The procedure was performed without maternal anesthesia. The site of sampling (umbilical vein) was assessed by ultrasonographic imaging with a $5-\mathrm{MHz}$ sector transducer, by determination of the nonpulsatile flow in the vessel, and by imaging the direction of flow by observing the bubbling effect produced by the injection of $2 \mathrm{~mL}$ of isotonic saline solution. Maternal arterialized blood was collected simultaneously. All fetuses had normal karyotypes and no malformations at birth. Estimated fetal weight was calculated by ultrasound (19).

Delivery. Thirty-five patients having singleton pregnancies were studied at the time of delivery, either by elective cesarean section (i.e. without spontaneous or induced uterine contractions, $n=25$ ) performed between 28 and 40 wk gestation after an overnight fast, or at the time of spontaneous delivery $(n=$ 10). Twelve normal pregnancies that terminated in the delivery of infants whose birth weights were AGA and eight pregnancies with maternal GDM were studied at the time of cesarean section. Indications for cesarean section were repeat cesarean section, breech presentation, or maternal indications; none of the babies showed signs of distress at delivery.

Five IUGR fetuses were studied at the time of cesarean section performed in the interest of the fetus. None of these

Table 1. Clinical characteristics of the population

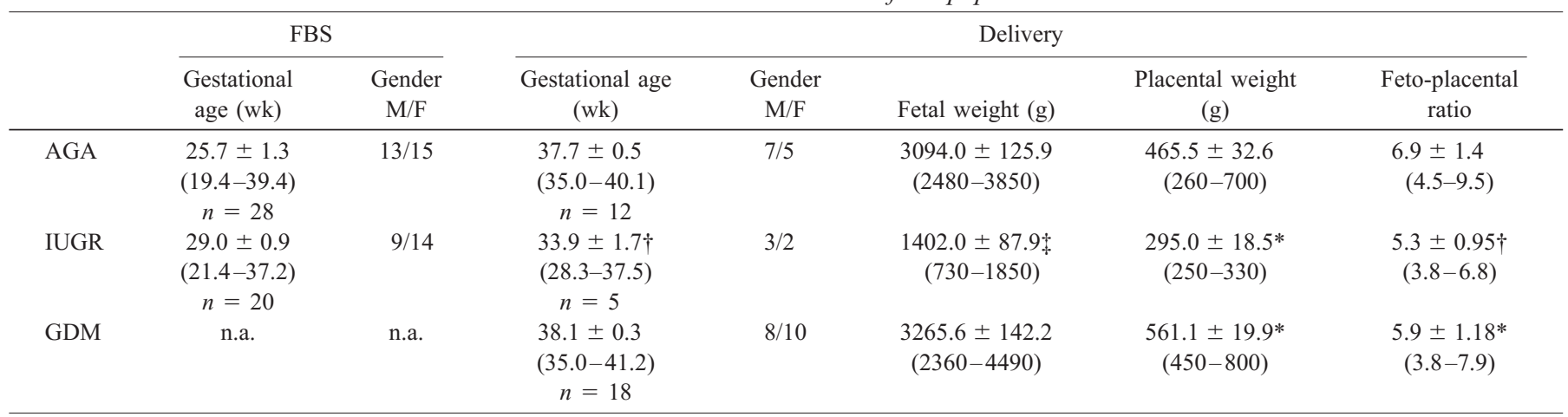

Mean $\pm \mathrm{SD}$ (range). $n=$ number of cases.

$* p<0.05$ vs AGA; $\dagger p<0.01$ vs AGA; $\$ p<0.001$ vs AGA.

n.a., not available. 
pregnancies were affected by preeclampsia or other maternal diseases. All fetuses had normal karyotypes and no malformations at birth.

In all cases, general anesthesia was used for the cesarean section. Umbilical arterial $(n=15)$ and venous blood samples were withdrawn from a doubly clamped segment of the cord immediately after fetal extraction.

Velocimetry and heart-rate measurement. As previously reported (18), IUGR fetuses were evaluated by assessment of Doppler velocimetry of the fetal umbilical artery and by FHR recordings performed immediately before FBS. Briefly, the waveform of the umbilical artery blood flow was measured with a coaxial pulsed Doppler velocimeter with a sample volume of $5 \mathrm{~mm}$ and high-pass filters set at $100 \mathrm{~Hz}$ (Ultramark 5, ATL Corp., Seattle, WA, U.S.A.), and the PI was measured according to the simplified Gosling formula (systolic velocity minus diastolic velocity divided by mean velocity) (20). The criteria used to evaluate FHR tracings were the degree of variability, the presence of accelerations from the baseline, and the presence of decelerations in heart rate after Braxton Hicks contractions. According to PI measurements and FHR patterns, IUGR fetuses were divided into the three subgroups we have previously described (18): group 1 (normal FHR and PI: 10 cases), group 2 (normal FHR, abnormal PI: 8 cases), and group 3 (abnormal FHR and PI: 7 cases).

Biochemical analyses. Fetal and maternal blood samples were collected into heparinized syringes that were immediately sealed and stored on ice. $\mathrm{Hb}$ concentration and oxygen saturation were measured in duplicate on a Radiometer OSM-3 Oxymeter (Copenhagen, Denmark); oxygen content was calculated from the above parameters according to the formula:

Oxygen content $(\mathrm{mM})$

$$
=\mathrm{Hb}(\mathrm{g} / \mathrm{L}) \times \text { oxygen saturation } \times 0.005982
$$

$\mathrm{pH}$ was measured on a Radiometer ABL 330 Analyzer (Copenhagen, Denmark). Glucose and lactate concentrations were measured in duplicate on a YSI 2300 STAT Plus analyzer (Yellow Springs Instruments, Yellow Springs, OH, U.S.A.).

Plasma for leptin analyses was separated by centrifugation at $3000 \mathrm{rpm}$ for $10 \mathrm{~min}$ at $-4^{\circ} \mathrm{C}$ and stored at $-70^{\circ} \mathrm{C}$. Plasma venous and arterial leptin concentrations were determined by a RIA using a commercial Kit (Human Leptin RIA Kit, LINCO Research, Inc., St. Louis, MO, U.S.A.). The detection limit was $0.5 \mathrm{ng} / \mathrm{mL}$. Intra- and interassay coefficients of variation were $6.2 \%$ and $8.3 \%$, respectively. All assays were run in duplicate, and the two measurements were averaged for statistical analysis.

Statistical analysis. Data are presented as mean \pm SD. The significance of the difference between groups was calculated with unpaired two-tailed $t$ test. The significance of the difference between umbilical artery and vein was calculated with a two-tailed $t$ test for paired samples. Linear and exponential regression analyses were performed by the least squares method.

\section{RESULTS}

\section{Plasma Leptin Concentrations in AGA Fetuses}

In AGA fetuses a significant relationship was found between leptin concentrations and gestational age, which was best represented by an exponential growth regression $(r=0.814$; $p<0.001$ ) (Fig. 1). Three fetuses sampled in utero before 23 wk presented measurable plasma leptin concentrations but below the detection limit of leptin assay $(0.5 \mathrm{ng} / \mathrm{mL})$.

A significant relationship was also found between leptin concentrations and fetal weight $(r=0.71 ; p<0.001)$ (Fig. 2).

Table 2 presents mean leptin concentrations and leptin concentration $/ \mathrm{kg}$ fetal weight (leptin/ $\mathrm{kg}$ ) in gestational age groups. In AGA fetuses, leptin concentrations increased significantly both between 19-26 and 27-33 wk, and between 27-33 and 34-41 wk.

No significant difference was observed between leptin concentrations in female and male fetuses in AGA (females = $2.0 \pm 2.4 \mathrm{ng} / \mathrm{mL}$; males $=1.9 \pm 1.8 \mathrm{ng} / \mathrm{mL}$ ) or when considering the entire population under study (females = $4.7 \pm 7.6 \mathrm{ng} / \mathrm{mL} ;$ males $=3.3 \pm 4.4 \mathrm{ng} / \mathrm{mL}$ ). Figure 1 presents umbilical venous leptin concentrations in female and male AGA in relation to gestational age. A significant relationship was observed in both female $(r=0.7 ; p<0.001)$ and male $(r=0.7 ; p<0.001)$ AGA fetuses.

In 10 term AGA fetuses, leptin concentrations were measured in both umbilical artery (ua) and umbilical vein (uv) and results were significantly higher in uv than in ua (uv $=4.1 \pm$ $2.4 \mathrm{ng} / \mathrm{mL}$; ua $=3.5 \pm 2.4 \mathrm{ng} / \mathrm{mL}, p<0.01)$. This led to a significantly positive umbilical venoarterial leptin concentration difference $(0.6 \pm 0.6 \mathrm{ng} / \mathrm{mL} ; p<0.01)$.

No significant relationship was observed between fetal and maternal leptin concentrations. No significant relationship was observed between umbilical venous leptin and plasma glucose concentrations.

\section{IUGR Fetuses}

The relationship between leptin concentrations in IUGR fetuses and fetal weight is shown in Figure $2(r=0.53$; $p<$ $0.05)$. A significant relationship was also observed with gestational age $(r=0.59 ; p<0.01)$. Mean leptin concentrations

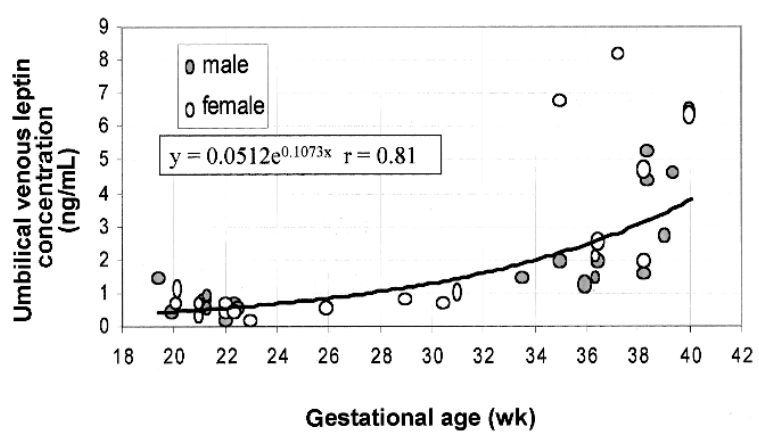

Figure 1. Circulating leptin concentrations in female (white ovals) and male (shaded ovals) AGA fetuses in relation to gestational age. Exponential growth regression: leptin $=0.052 \mathrm{e}^{0.1069} \times$ gestational age; $r=0.814 ; r^{2}=0.6625$; $p<0.001$. 


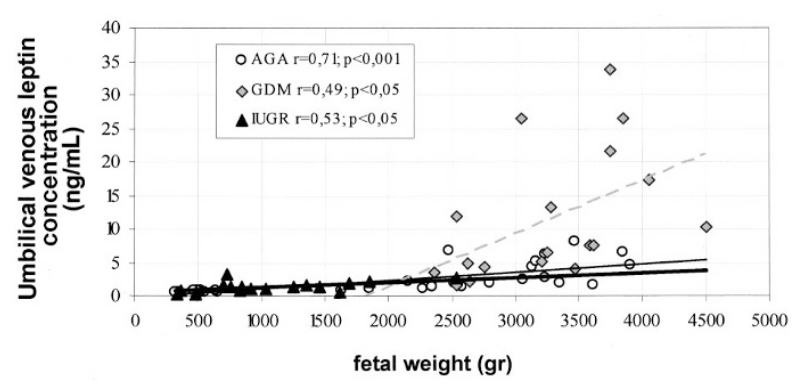

Figure 2. Circulating leptin concentrations in AGA (○), IUGR ( $\mathbf{\Delta})$, and $\operatorname{GDM}(\diamond)$ fetuses in relation to fetal weight. For AGA: leptin $=-0.17+0.001$ $\times$ fetal weight; $r=0.7 ; r^{2}=0.5 ; p<0.001$. For IUGR: leptin $=0.62+$ $0.0007 \times$ fetal weight; $r=0.58 ; r^{2}=0.28, p<0.05$. For GDM: leptin $=$ $-14.2+0.008 \times$ fetal weight; $r=0.49 ; r^{2}=0.24 ; p<0.05$.

Table 2. Umbilical venous leptin concentrations in AGA, IUGR, and GDM fetuses in gestational age groups

\begin{tabular}{|c|c|c|c|c|}
\hline & \multirow{2}{*}{$\begin{array}{c}\text { 19-26 wk } \\
\text { uv Leptin } \\
(\mathrm{ng} / \mathrm{mL})\end{array}$} & \multirow{2}{*}{$\begin{array}{c}\text { 27-33 wk } \\
\text { uv Leptin } \\
(\mathrm{ng} / \mathrm{mL})\end{array}$} & \multicolumn{2}{|c|}{$\geq 34$ wk } \\
\hline & & & $\begin{array}{c}\text { uv Leptin } \\
\text { (ng/mL) }\end{array}$ & $\begin{array}{c}\text { uv Leptin } / \mathrm{kg} \\
\text { (ng/mL/kg) }\end{array}$ \\
\hline AGA & $\begin{array}{c}0.6 \pm 0.3 \\
(<0.5-1.4) \\
n=19\end{array}$ & $\begin{array}{c}1.0 \pm 0.3^{*} \\
(0.7-1.4) \\
n=4\end{array}$ & $\begin{array}{c}3.8 \pm 2.2 \dagger \\
(1.2-8.2) \\
n=17\end{array}$ & $\begin{array}{c}1.1 \pm 0.6 \\
(0.4-2.4) \\
n=15\end{array}$ \\
\hline IUGR & $\begin{array}{c}0.5 \pm 0.2 \\
(<0.5-0.9)\end{array}$ & $\begin{array}{c}1.3 \pm 0.7 \S \\
(<0.5-3.3) \\
n=13\end{array}$ & $\begin{array}{l}1.8 \pm 0.79 \\
(0.6-2.7)\end{array}$ & $\begin{array}{c}0.9 \pm 0.4 \\
(0.4-1.2)\end{array}$ \\
\hline GDM & n.a. & n.a. & $\begin{array}{c}11.6 \pm 9.7 \ddagger \\
(1.6-33.9) \\
n=18\end{array}$ & $\begin{array}{c}3.4 \pm 2.6 \ddagger \\
(0.6-9.0) \\
n=18\end{array}$ \\
\hline
\end{tabular}

Mean \pm SD (range). $n=$ number of cases.

$* p<0.05$ vs AGA 19-26 wk; $\dagger p<0.05$ vs AGA 27-33wk; $\ddagger p<0.01$ vs AGA; $\S p<0.05 v s$ IUGR 19-26 wk; $₫ p<0.05$ vs AGA.

n.a., not available.

increased significantly between $19-26$ and $27-33$ wk, but not after 34 wk (Table 2).

When compared with AGA fetuses of similar gestational age, leptin concentrations were significantly lower in IUGR than in AGA after 34 wk (Table 2), but no significant differences were observed between AGA and IUGR when adjusting for fetal weight (leptin $/ \mathrm{kg})$.

Table 3 presents data for IUGR subdivided in three groups according to the classification previously presented. No significant differences were observed between IUGR fetuses of groups 1 and 2, whereas significantly higher lactate concentra- tions were observed in IUGR fetuses of group 3. Leptin $/ \mathrm{kg}$ in these fetuses were significantly higher than in group 1 (Table $3)$.

\section{Fetuses from GDM Pregnancies}

Similar to AGA and IUGR fetuses, a significant relationship was observed in these fetuses between leptin concentrations and fetal weight $(r=0.49 ; p<0.05)$ (Fig. 2). Leptin concentrations and leptin/kg fetal weight were significantly higher in GDM fetuses when compared with AGA fetuses after 34 wk (Table 2). These differences were also observed when considering only those GDM fetuses with birth weights within the normal range (leptin $=11.3 \pm 9.9 \mathrm{ng} / \mathrm{mL} ; n=13$ ).

Figure 3 presents the relationship between leptin concentrations and fat abdominal thickness measured by ultrasound in the week before delivery in 12 GDM fetuses. When abdominal thickness did not exceed the value of $54 \mathrm{~mm}$ (mean $+1 \mathrm{SD}$ in normal term pregnancies) (Cetin I, Radaelli T, Taricco E, unpublished observations), leptin concentrations all fell within the normal range (below $6 \mathrm{ng} / \mathrm{mL}=$ mean +1 SD for AGA term fetuses), whereas they were significantly higher in those GDM fetuses with concomitant higher fat mass at the level of the abdominal wall.

\section{DISCUSSION}

The present study confirms and expands previous observations that leptin is present in the fetal circulation beginning in the second trimester of pregnancy. Fetal plasma leptin concentrations increase significantly throughout gestation, particularly after $34 \mathrm{wk}$, when there is also a very significant increase in fetal body fat mass (21). However, because leptin concentrations increase significantly in umbilical venous plasma throughout the second half of gestation and fetal plasma leptin is also significantly related to fetal weight, it is difficult to dissect whether there is a gestational age shift in the fetal production of leptin in normal pregnancies. Moreover, in normal term pregnancies carrying AGA fetuses, leptin concentrations are significantly higher in the umbilical vein than in the artery, indicating placental contribution to fetal circulating leptin accounting for concentrations in the umbilical vein approximately $20 \%$ above those in the umbilical artery.

Table 3. Gestational age, gender, umbilical vein $\mathrm{O}_{2}$ content, pH, lactate concentration, leptin concentration, and leptin concentration/kg fetal weight in IUGR pregnancies subdivided according to FHR and PI

\begin{tabular}{|c|c|c|c|c|c|c|c|}
\hline & $\begin{array}{l}\text { Gestational age } \\
\text { (wk) }\end{array}$ & $\begin{array}{c}\text { Gender } \\
\mathrm{M} / \mathrm{F}\end{array}$ & $\mathrm{O}_{2}$ Content & $\mathrm{pH}$ & $\begin{array}{c}\text { Lactate } \\
(\mathrm{mmol} / \mathrm{mL})\end{array}$ & $\begin{array}{l}\text { Leptin } \\
(\mathrm{ng} / \mathrm{mL})\end{array}$ & $\begin{array}{c}\text { Leptin } / \mathrm{kg} \\
(\mathrm{ng} / \mathrm{mL} / \mathrm{kg})\end{array}$ \\
\hline $\begin{array}{l}\text { IUGR } 1 \\
n=10\end{array}$ & $\begin{array}{c}29.6 \pm 6.0 \\
(21.4-37.5)\end{array}$ & $5 / 5$ & $\begin{array}{c}5.4 \pm 1.5 \\
(2.9-7.0) \\
n=9\end{array}$ & $\begin{array}{l}7.37 \pm 0.03 \\
(7.34-7.43)\end{array}$ & $\begin{array}{c}1.13 \pm 0.50 \\
(0.57-1.90) \\
n=7\end{array}$ & $\begin{array}{c}1.0 \pm 0.9 \\
(<0.5-2.7)\end{array}$ & $\begin{array}{c}1.0 \pm 0.2 \\
(0.6-1.2) \\
n=5\end{array}$ \\
\hline $\begin{array}{l}\text { IUGR } 2 \\
n=8\end{array}$ & $\begin{array}{c}31.4 \pm 4.3 \\
(23.4-36.1)\end{array}$ & $4 / 4$ & $\begin{array}{c}5.7 \pm 1.9 \\
(2.9-7.0) \\
n=7\end{array}$ & $\begin{array}{c}7.34 \pm 0.06 \\
(7.34-7.43) \\
n=7\end{array}$ & $\begin{array}{c}1.29 \pm 0.46 \\
(0.57-1.90) \\
n=5\end{array}$ & $\begin{array}{c}1.2 \pm 0.5 \\
(<0.5-1.9)\end{array}$ & $\begin{array}{c}1.1 \pm 0.5 \\
(0.4-2.0) \\
n=7\end{array}$ \\
\hline
\end{tabular}

Mean \pm SD (range). $n=$ number of cases.

$* p<0.05$ vs IUGR1. 


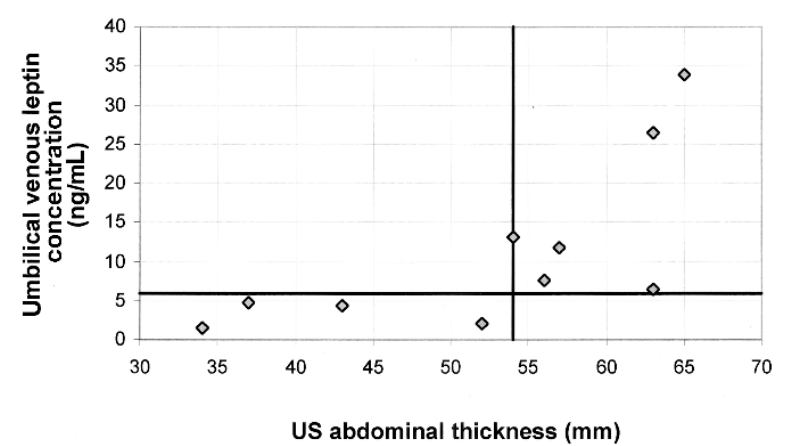

Figure 3. Circulating leptin concentrations in fetuses from GDM pregnancies in relation to in utero measurements of fetal fat abdominal thickness by ultrasound. The vertical and horizontal lines represent the mean $+1 \mathrm{SD}$ of ultrasound abdominal thickness and umbilical venous leptin concentrations, respectively, measured in normal pregnancies.

In adults, leptin concentrations are significantly higher in normal weight females than in males, so that leptin normalized to fat mass is two to three times higher in females than in males $(4,22)$. However, our study, in agreement with a number of previous studies $(7,9-11,23)$, did not find significant differences in cord blood leptin concentrations in relation to gender. In the only previous study (24) that reported significantly higher leptin concentrations in female than in male cord blood, in utero growth was not investigated and females had significantly heavier placentas than the males, suggesting that their intrauterine growth patterns were different. The lack of differences in relation to gender during intrauterine life has also been reported previously for androgens and for fetal gonadotropin concentrations (25).

In the present study, leptin concentrations varied significantly in relation to the intrauterine pattern of fetal growth. Fetuses from gestational diabetes pregnancies showed significantly higher leptin concentrations also when fetal weights were within the normal range. In these fetuses, leptin concentrations per kilogram fetal weight were three times higher than in normal pregnancies. These findings suggest that the increase in fetal fat mass is associated with increased fetal leptin production, and this is confirmed by the highest leptin concentrations found in those GDM fetuses with increased in utero measurements of abdominal fat thickness. The placenta might also be responsible, in part, for this increased production, inasmuch as placental weights were significantly higher in GDM pregnancies.

Previous studies have focused on leptin concentrations in IUGR $(8-10)$, reporting lower $(8,10)$ or higher (9) leptin concentrations in IUGR fetuses. In our study, leptin concentrations were significantly lower in IUGR than in AGA fetuses after 34 wk but no significant differences were observed in IUGR of earlier gestation. Moreover, when adjusting for fetal weight, IUGR leptin concentrations were not significantly different from AGA of similar gestational age. The same finding was reported by Koistinen et al. (8) in IUGR at term. However, Shekawat et al. found significantly higher cord leptin concentrations in term IUGR compared with birth weightmatched AGA infants (9).

We have previously shown that IUGR can be classified in three groups according to biophysical parameters and that these groups represent progressive severity according to biochemical data obtained in utero (18). It is very interesting that, according to this classification, IUGR fetuses with normal oxygenation and fetalbase balance present leptin concentrations similar to AGA fetuses per kilogram fetal weight, whereas those with more severe signs of fetal distress have significantly higher leptin concentrations per kilogram fetal weight. Because it is well known that fat mass in these fetuses is poorly represented, it is difficult to explain these findings. However, there are many potential explanations, among which is the presence of elevated levels of endogenous corticosteroid hormones $(26,27)$ leading to an increased leptin synthesis (28). Moreover, one might speculate on the role of the placenta, in that the regulation of placental leptin production is not understood yet, but could be associated with changes in relation to glucose and insulin and eventually could be linked to the transfer of glucose and amino acids, which are known to be altered in IUGR $(29,30)$.

In summary, our data indicate that leptin is present in fetal plasma as early as $19 \mathrm{wk}$ and that their concentrations increase significantly with gestation and with increased fetal weight. Maternal gestational diabetes is associated with increased percent fetal fat mass and increased fetal leptin concentrations, whereas in IUGR fetuses leptin concentrations are not different proportionally to fetal weight, but are significantly higher per $\mathrm{kg}$ fetal weight in the presence of hypoxia and lactacidemia, possibly due to the activation of pituitary-adrenal axis. The regulation of fetal and/or placental production of leptin and its role in IUGR has still to be determined.

Finally, the suggestion that leptin levels per se may play a role in fetal growth is still a matter of debate. The findings of normal neonatal weight and height in patients with leptin mutations (6) seem to militate against such a direct role.

\section{REFERENCES}

1. Zhang Y, Proneca R, Maffei M, Barone M, Leopold L, Friedman JM 1995 Positional cloning of the mouse obese gene and its human homologue. Nature 372:425-432

2. Halaas JL, Gajiwala KS, Maffei M, Cohen SL, Chait BT, Rabinowitz D, Lallone RL, Burley SK, Friedman JM 1995 Weight-reducing effects of the plasma protein encoded by the obese gene. Science 269:540-543

3. Kennedy A, Gettys TW, Wason P, Wallace P, Ganaway E, Pan Q, Garvey WT 1997 The metabolic significance of leptin in humans: gender-based differences in relationship to adiposity, insulin sensitivity and energy expenditure. J Clin Endocrinol Metab 82:1293-1300

4. Saad MF, Damani S, Gingerich RL, Riad-Gabriel MG, Khan A, Boyadjian R, Jinagouda SD, el-Tawil K, Rude RK, Kamdar V 1997 Sexual dimorphism in plasma leptin concentration. J Clin Endocrinol Metab 82:579-584

5. Chehab FP, Lim ME, Lu R 1996 Correction of the sterility defect in homozygous obese female mice by treatment with the human recombinant leptin. Nat Genet $12: 318-320$

6. Farooqi IS, Jebb SA, Langmack G, Lawrence E, Cheetham CH, Prentice AM, Hughes IA, McCamish MA, O'Rahilli S 1999 Effects of recombinant leptin therapy in a child with congenital leptin deficiency. N Engl J Med 341:879-884

7. Schubring C, Kiess W, Englaro P, Rascher W, Dotsch J, Hanitsch S, Attanasio A, Blum WF 1997 Levels of leptin in maternal serum, amniotic fluid, and arterial and venous cord blood: relation to neonatal and placental weight. J Clin Endocrinol Metab $82: 1480-1483$

8. Koistinen HA, Koivisto VA, Andersson S, Karonen S-L, Kontula K, Oksanen L, Teramo KA 1997 Leptin concentration in cord blood correlates with intrauterine growth. J Clin Endocrinol Metab 82:3328-3330

9. Shekawat PS, Garland JS, Shivpuri C, Mick GJ, Sasidharan P, Pelz CJ, Mc Cormick KL 1998 Neonatal cord blood leptin: its relationship to birth weight, body mass index, maternal diabetes, and steroids. Pediatr Res 43:338-343

10. Jaquet D, Leger J, Levy-Marchal C, Oury JF, Czernichow P 1998 Ontogeny of leptin in human fetuses and newborns: effect of intrauterine growth retardation on serum leptin concentrations. J Clin Endocrinol Metab 83:1243-1246

11. Varvarigou A, Mantzoros CS, Beratis NG 1999 Cord blood leptin concentrations in relation to intrauterine growth. Clin Endocrinol 50:177-183

12. Clapp III JF, Kiess W 1998 Cord blood leptin reflects fetal fat mass. J Soc Gynecol Invest 5:300-303 
13. Yura S, Sagawa N, Mise H, Mori T, Masuzaki H, Ogawa Y, Nakao K 1998 A positive umbilical venous-arterial difference of leptin level and its rapid decline after birth Am J Obstet Gynecol 178:926-930

14. Parazzini F, Cortinovis I, Bortolus R, Fedele L 1991 Standard di peso alla nascita in Italia. Ann Ost Gin Med Perin CXII:203-246

15. Todros T, Ferrazzi E, Groli C, Nicolini U, Parodi L, Pavoni M, Zorzoli A, Zucca S 1987 Fitting growth curves to head and abdomen measurements of the fetus: a multicentric study. J Clin Ultrasound 15:95-105

16. Coustan DR 1994 Screening and diagnosis of gestational diabetes. Semin Perinatol 18:407-413

17. Marconi AM, Cetin I, Buscaglia M, Pardi G 1992 Midgestation cord sampling: what have we learned. Placenta 13:115-122

18. Pardi G, Cetin I, Marconi AM, Lanfranchi A, Bozzetti P, Ferrazzi E, Buscaglia M, Battaglia FC 1993 Diagnostic value of blood sampling in fetuses with growth retardation. N Engl J Med 328:692-696

19. Hadlock FP, Harrist RB, Carpenter RJ, Deter RL, Park SK, 1984 Sonographic estimation of fetal weight. The value of femur length in addition to head and abdomen measurements. Radiology 150:535-540

20. Gosling RG, King DH 1974 Continuous wave ultrasound as an alternative and complement to x-rays in vascular examinations. In: Reneman RS (ed) Cardiovascular Applications of Ultrasound. North Holland, Amsterdam, pp 266-282

21. Enzi G, Zanardo V, Caretta F, Inelmen EM, Rubaltelli F 1981 Intrauterine growth and adipose tissue development. Am J Clin Nutr 34:1785-1790

22. Rosenbaum M, Nicolson M, Hirsch J, Heymsfield SB, Gallagher D, Chu F, Leibel RL 1996 Effects of gender, body composition, and menopause on plasma concentrations of leptin. J Clin Endocrinol Metab 81:3424-3427
23. Harigaya A, Nagashima K, Nako Y, Morikawa A 1997 Relationship between concentration of serum leptin and fetal growth. J Clin Endocrinol Metab 82:32813284

24. Tome MA, Lage M, Camina JP, Garcia-Mayor RV, Dieguez C, Casanueva FF 1997 Sex-based differences in serum leptin concentrations from umbilical cord blood at delivery. Eur J Endocrinol 137:655-658

25. Beck-Peccoz P, Padmanabhan V, Baggiani AM, Cortelazzi D, Buscaglia M, Medri G, Marconi AM, Pardi G, Beitins IZ 1991 Maturation of hypothalamic-pituitary-gonadal function in normal human fetuses: circulating levels of gonadotropins, their common a-subunit and free testosterone, and discrepancy between immunological and biological activities of circulating follicle-stimulating hormone. J Clin Endocrinol Metab 73:525-532

26. Parker CR, Buchina ES, Barefoot TK 1994 Abnormal adrenal steroidogenesis in growth retarded newborn infants. Pediatr Res 35:633-636

27. Harlin CA, Tucker JM, Winkler CL, Parker CR 1993 Altered adrenal steroid production in term infants having respiratory acidosis. Acta Endocrinol 128:136-139

28. Slieker LJ, Sloop KW, Surface PL, Kriauciunas A, Laquier F, Manetta J, Valleskey JB, Stephens TW 1996 Regulation of expression of ob-mRNA and protein by glucocorticoids and cAMP. J Biol Chem 271:5301-5304

29. Marconi AM, Paolini C, Buscaglia M, Zerbe G, Battaglia FC, Pardi G 1996 The impact of gestational age and of fetal growth upon the maternal-fetal glucose concentration difference. Obstet Gynecol 87:937-942

30. Cetin I, Ronzoni S, Marconi AM, Perugino G, Corbetta C, Battaglia FC, Pardi G 1996 Maternal concentrations and fetal-maternal concentration differences of plasma amino acids in normal (AGA) and intrauterine growth restricted pregnancies. Am J Obstet Gynecol 174:1575-1583 